\title{
Women's practices in terms of breast cancer early screening and the health professional's role in the sensitization, Agadir (Morocco)
}

\begin{abstract}
Our study aims to describe the knowledge and the practices of women from Agadir (Morocco) related to breast cancer screening and analyze the health professional's role in sensitization. Almost all women know breast cancer; however, the practice of screening is deficient. The health professionals have reflected a modest level in knowledge. The midwives interviewed indicate that they invite women to the self-examination of breast. More efforts are yet required to promote the practice of breast cancer screening in women. Health professionals should be concerned more in education and information to enlarge screening, especially for high-risk women.
\end{abstract}

Keywords: breast cancer, practice, screening, sensitization
Volume 6 Issue 3 - 2016

\author{
Smail Chadli, ${ }^{1,2}$ Naima Taqarort, ${ }^{3}$ Lhabib \\ Nmili, ${ }^{4}$ Said Oulkheir ${ }^{\prime}$ \\ 'Higher Institute of Nursing Professions and Health Techniques, \\ Morocco \\ ${ }^{2}$ Laboratory of Cellular Biology and Molecular Genetics, Ibn \\ Zohr University, Morocco \\ ${ }^{3}$ Polydisciplinary faculty of Taroudant, Ibn Zohr University, \\ Morocco \\ ${ }^{4}$ Regional Blood Transfusion Center, Hassan2 Hospital, Morocco
}

Correspondence: Smail Chadli, Higher Institute of Nursing Professions and Health Techniques, ISPITS- Agadir, Morocco, Tel 2I2663 II2 099, Fax 212 528843987.

Emailschadli@gmail.com

Received: October 26, 2016 | Published: December 14, 2016

\section{Introduction}

Breast cancer is a serious problem of public health. It represents the first female cancer in the developed countries and it's the best cause of cancer deaths in women. In developing countries, its incidence is growing and the majority of breast cancer cases are diagnosed in advanced stages. ${ }^{1}$ Early detection activities are very important in reducing the incidence of cancers. It is particularly important that women are regularly screened to grow up the chance that a breast cancer is detected early before it has spread. ${ }^{1}$ By means of efficient information programs and early detection, morbidity and mortality related to breast cancer may be reduced. In Morocco, as is the case in developed countries, a National Prevention and Control of Cancer Plan (NPCCP) have existed since 2010. The objective of this ambitious NPCCP is to reduce the cancer prevalence and the mortality rate, and to improve the patients' quality of life as well as that of their relatives. $^{2}$

The efficiency of a screening program is determined largely by the level of participation and degree of adhesion of women. This adhesion to screening program rely on the women's knowledge and practices toward the breast and the screening. The American Cancer Society recommends that all women should become familiar with the potential benefits, limitations, and harms associated with breast cancer screening. ${ }^{3}$ An important role was assigned to the health professionals in the program to motivate women to adhere to screening. This is a responsibility of great importance especially for doctors, midwives and nurses. If the health professionals were themselves trained and sensitized, they can motivate and recommend the women concerned to participate in organized screening. They can also contribute to physical breast analysis, learning to women self-breast examination and orientation of women in mammography centers.

The aims of our study are to describe the knowledge and the practices of Moroccan women (Agadir) toward breast cancer screening and analyze the health professional's role in sensitization and motivation of women to adhere to screening program.

\section{Conclusion}

This is a descriptive cross-sectional study in 2016. Two questionnaires were used: one was completed by a sample of 200 women who consulted at two health center in Agadir region. Second was filled by all health professionals of these structures.

Our study shows that $92 \%$ of women have the age between $15-45$ and $94 \%$ are married. $91 \%$ of women are from the urban. The level of education was primary and secondary in $72 \%$ of cases $(18 \%$ illiterate, $10 \%$ higher level of education). The use of orally contraceptive was noted in $80 \%$ of participants. $93 \%$ of the study population was living in an environment with tobacco. Breastfeeding was practiced in $66 \%$ of women interviewed.

$99 \%$ of women interviewed know breast cancer and 65\% say that all women are susceptible to have breast cancer. There is then sufficient knowledge of breast cancer; however, only $32 \%$ of women have conducted screening. The media are the most cited as the information source (64\%). The campaigns advertising on television on breast cancer would be an important element in promotion of the knowledge level. After 6 years of starting the screening program, health professionals only constitute $10 \%$ of the patient sources about breast cancer. More efforts are needed to improve the contribution of health professionals to breast cancer screening, particularly the need for continuing education in future programs. Regarding women's knowledge of the different modes of screening, the mammography is least known (9\%), followed by breast self-examination (30\%) and in first place breast examination by health professionals $(51 \%)$. $10 \%$ do not know any detection methods. The participation rates in breast cancer screening activities were low. Although data related to breast cancer screening among Arab woman is scarce, in a recent 
study of Qatari citizens and non-Qatari residents, it was discovered participation rates in breast cancer screening activities were low; $28,9 \%$ were aware of breast self-examination, $41,8 \%$ were aware of clinical breast exams, and $26,9 \%$ were aware of mammograms. ${ }^{4}$ The role of health professionals appears essential for these women.

A second questionnaire is adopted to explore the health professional's role. All health professionals believe that breast cancer is a major public health problem in Morocco. They are agreeing on the importance of their participation to early detection activities and their powerful role in motivating women to participate in breast cancer screening. $60 \%$ of health professionals interviewed are midwives. They say they inform women on the importance of only self-examination. They consider it the best method of breast cancer screening. The health professionals have reflected a modest level in knowledge. This is consistent with the results of Charaka et al. ${ }^{5}$

These results lead us to consider two major parameters for the success of a screening program and increased level of participation and degree of adhesion of women. First, it is necessary to improve women's knowledge about breast cancer screening and act on psychological-sociocultural factors influencing the adhesion women to the screening program. Second, the health professionals should play a powerful role in motivating women to participate in breast cancer screening. They should be involved more in education and information to promote screening, especially for high-risk women. The development of knowledge and a positive conduct in terms of breast cancer screening among health professionals should begin in the early years of medical and paramedical studies, in places of practical training, and must be uninterrupted through continuing education.

\section{Acknowledgments}

None.

\section{Conflicts of Interset}

Authors declare there are no conflicts of interest.

\section{References}

1. American Cancer Society. Breast Cancer Facts \& Figures 2015-2016. American Cancer Society: Atlanta; 2015.

2. National Prevention and Control of Cancer Plan 2010-2019. The Foundation Lalla Salma Cancer prevention and treatment and Ministry of Health: Morocco; 2009. 69 p.

3. Oeffinger KC, Fontham E, Etzioni R, et al. Breast Cancer Screening for Women at Average Risk: 2015 Guideline Update from the American Cancer Society. JAMA. 2015;14(15):1599-1614.

4. Donnelly TT, Al-Khater AH, Al-Bader SB, et al. Breast cancer screening among Arabic women living in the State of Qatar: Awareness, knowledge, and participation in screening activities. Avicenna. 2012;2.

5. Charaka H, Khalis M, Aghlallou Y, et al. Connaissances et participation des infirmiers aux activités de détection précoce du cancer du sein au Maroc. Revue d'Epidémiologie et de santé publique. 2015;63(2):S69S70 